\title{
CURRÍCULO TEMÁTICO FUNDAMENTADO EM FREIRE-CTS: ENGAJAMENTO DE PROFESSORES DE FÍSICA EM FORMAC̦ÃO INICIAL ${ }^{1,2}$
}

RESUMO: Este trabalho resultou da reflexão sobre vivência de professores(as) de física, em formação inicial, com a abordagem temática fundamentada em Freire-CTS. Buscamos responder à pergunta: como professores(as) em formação inicial posicionamse frente à possibilidade de realizar encaminhamentos curriculares pautados pela abordagem temática durante seu estágio curricular e/ou no decorrer da sua atuação profissional? Utilizamos a Análise Textual Discursiva para analisar questionários respondidos por esses professores(as) ao final do trabalho. Como resultados, identificamos três categorias articuladas ao currículo: (i) da fragmentação disciplinar à interdisciplinaridade, (ii) temas da realidade dos estudantes como ponto de partida e (iii) abordagem temática: reconfiguração curricular ou nova metodologia? Ao final, sinalizamos desafios e potencialidades de currículos temáticos.

Palavras-Chave: Currículo Temático. Freire-CTS. Professores de física em formação inicial.

\section{THEMATIC CURRICULUM BASED ON FREIRE-STS: ENGAGEMENT OF PHYSICS TEACHERS IN INITIAL TRAINING}

ABSTRACT: This work resulted from reflection about physics teachers' experience in initial training, with the thematic approach based on Freire-STS (Paulo Freire's Science - Technology Society). We seek to answer the question: How teachers in initial training place themselves front of the possibility of performing curricular referrals guided by the thematic approach during his/ hers traineeship and/or in the course of their professional practice? We use the Discursive Textual Analysis to analyze questionnaires answered by those teachers at the end of the work. We identified three categories articulated to the curriculum as a result: (i) from the disciplinary fragmentation to the interdisciplinarity, (ii) issues of students' reality as a starting point, and (iii) thematic approach: curricular reconfiguration or new methodology? At the end, we signaled potentialities and challenges of thematic curriculum.

Keywords: Thematic Curriculum, Freire-STS, Physics Teachers in Initial Training.

\author{
Caetano Castro Roso* \\ Rosemar Ayres dos Santos** \\ Suiane Ewerling da Rosa** \\ Décio Auler**** \\ * Programa de Pós-Graduação em \\ Educação Científica e Tecnológica \\ da Universidade Federal de Santa \\ Catarina; Doutorando (PPGECT) \\ UFSC); Mestre em Educação pela \\ Universidade Federal de Santa Maria \\ (UFSM); Licenciado em Física pela \\ E-mail: caetanoroso@gmail.com. \\ ** Universidade Federal da Fronteira \\ Sul e Programa de Pós-Graduação \\ em Educacão da UFSM; Doutoranda \\ (PPGE/UFSMM); Mestre em Educação \\ pela UFSM; Licenciada em Física \\ E-mil: pela UFSM. \\ *** Instituto Federal da Bahia; \\ Mestre em Educação pela UFSM; \\ Licenciada em Física pela UFSM. \\ E-mail: suiedr@gmail.com. \\ * ** Programa de pós-graduação \\ em educação da UFSM; Doutor em \\ Educacấo pela UFSC; Mestre em \\ Educaçãa pela UFSM; Licenciado em \\ Física pela UNISC \\ E-mail: auler.ufsm@gmail.com
}




\section{CURRÍCULO TEMÁTICO FUNDAMENTADO EN FREIRE-CTS: ENGAJAMIENTO DE MAESTROS DE FÍSICA EN FORMACIÓN INICIAL}

RESUMEN: Este trabajo resulta de la reflexión acerca de la vivencia de maestros de física en formación inicial, con abordaje temático fundamentado en Freire-CTS (Ciencia-Tecnología-Sociedad). Buscamos contestar a la pregunta: ¿Cómo maestros y maestras en formación inicial se posicionan frente a la posibilidad de realizar referencias curriculares alineadas por el abordaje temático durante su pasantía curricular y/o a lo largo de su actuación profesional? Utilizamos el Análisis Textual Discursivo para analizar cuestionarios respondidos por eses maestros y maestras al final del trabajo. Como resultados, identificamos tres categorias articuladas al currículo: (i) de la fragmentación disciplinaria a la interdisciplinaridad, (ii) temas de la realidad de los estudiantes como punto de partida y (iii) abordaje temático: ¿reconfiguración curricular o nueva metodología? Al final, señalamos desafíos y posibilidades de currículos temáticos.

Palabras clave: Currículo temático. Freire-CTS, Maestros de Física en Formación Inicial 


\section{JUSTIFICATIVA E DELIMITAÇÃO DO PROBLEMA DE PESQUISA}

Evasão, repetência e ausência de significado: problemas que, aliados à constituição de uma cultura de passividade, constituem desafios, cada vez mais presentes na educação brasileira, particularmente no ensino de física. Historicamente, com recorrentes fracassos, têm-se buscado soluções no campo metodológico. Entendemos que o enfrentamento desses e de outros dilemas remete para o campo do currículo. Campo não neutro, mas marcado por intencionalidades, por disputas entre concepções educacionais e entre concepções de sociedade.

Cresce a compreensão, também no âmbito da educação em ciências, de que o campo da didática é insuficiente para compreender e enfrentar os graves problemas educacionais. Charlot (2009), por exemplo, relaciona a evasão escolar ao exagero na ênfase dada à didática, geralmente desvinculada do campo sociológico. Sobre a didática destaca que "[...] ela supõe já dado o eu epistêmico, ou seja, a razão humana, um espírito querendo aprender, um aluno intelectualmente mobilizado" (CHARLOT, 2009, p. 21). Para o autor, somente ocorre aprendizagem quando alguém se mobiliza numa atividade intelectual e "só se mobiliza numa atividade intelectual quem acha um sentido nela" (CHARLOT, 2009, p. 29).

Nesse sentido, entendemos que há uma lacuna, um vácuo no processo educacional. Lacuna associada ao querer conhecer, o que Freire (1992) denomina de curiosidade epistemológica e Charlot (2009) de estar mobilizado intelectualmente. Em Freire (1992), o querer conhecer antecede o conhecer. Para esse educador, ignorar saberes de experiência feitos como ponto de partida, como objeto de problematização, provoca o erro epistemológico.

Currículos temáticos, particularmente quando inspirados em pressupostos freireanos, têm sido praticados como encaminhamento para o enfrentamento desses e de outros desafios presentes na educação, conforme Freire (2005), Delizoicov et al.(2002) e Watanabe-Caramelo et al. (2012). Segundo Delizoicov et al. (2002, p. 189), a abordagem temática consiste numa "perspectiva curricular cuja lógica de organização é estruturada com base em temas, com os quais são selecionados os conteúdos de ensino das disciplinas. Nessa abordagem, a conceituação científica da programação é subordinada ao tema".

Repensar a educação, repensar currículos, tendo como eixo estruturante a abordagem temática, constitui-se algo em crescimento. Estão em curso, no contexto brasileiro, práxis educacionais estruturadas com fundamentação teórico-metodológica resultante de uma aproximação crítica entre o pensamento educacional freireano e pressupostos de encaminhamentos do denominado movimento Ciência-Tecnologia-Sociedade (CTS). Nesse sentido, destacamos os trabalhos de Auler (2002 e 2007), Dalmolin et al. (2011), Monteiro et al. (2010), Nascimento e Von Linsingen (2006), Rosa et al. (2012), Roso (2014), Roso et al. (2011), Santos (2008), Santos et al. (2010) e Strieder (2012).

Contudo, conceber e executar currículos temáticos demanda desafios, por exemplo, para a formação de professores - desafios motivadores da pesquisa que 
apresentamos neste artigo. Assim, o trabalho desenvolvido constituiu-se de duas dimensões interdependentes: (i) desenvolvimento de um tema, com duas turmas de professores em formação de um curso de Licenciatura em Física na disciplina de Didática da Física, bem como discussões sobre concepções curriculares fundamentadas em Freire-CTS e (ii) avaliação de suas compreensões quanto a um possível engajamento em práxis educacionais pautadas por currículos temáticos, através de questionários respondidos ao final das atividades. O tema desenvolvido foi "Sol, Luz e Vida" (SLV), descrito no subitem seguinte.

A avaliação quanto a um possível engajamento desses professores em formação e a reflexão sobre todo o processo estiveram balizadas pelo problema de pesquisa: como professores, em formação inicial, posicionam-se frente à possibilidade de realizar encaminhamentos curriculares pautados pela abordagem temática, durante seu estágio curricular e/ou no decorrer da sua atuação profissional? Em termos de detalhamento do problema, nossos objetivos foram (i) identificar e analisar as manifestações de professores, em formação inicial, quanto ao desenvolvimento de conhecimentos vinculados à temática Sol, Luz e Vida, (ii) identificar e analisar contribuições e lacunas para a formação desses profissionais e (iii) sinalizar encaminhamentos para a educação em ciências, no sentido de contemplar abordagens curriculares balizadas pela aproximação Freire-CTS.

\section{TEMA “SOL, LUZ E VIDA”}

A temática "Sol, luz e vida" tem sua gênese no desdobramento de tema anterior, "Modelos de transporte: Implicações socioambientais" (AULER et al., 2005), definido a partir de duas situações. A primeira é a polêmica surgida no Rio Grande do Sul envolvendo a privatização de empresas públicas e a posterior concessão de uma série de vantagens sob a forma de incentivos e isenção fiscal a determinada empresa. A segunda situação foi uma investigação temática realizada quanto ao modelo de transporte utilizado por estudantes da Educação de Jovens e Adultos em seu deslocamento para a escola. Uma etapa intermediária, entre a temática "Modelos de transporte" e o processo de estruturação da atual temática (SLV), consistiu na identificação, estruturação e implementação de outras temáticas: "Bicicleta como meio de transporte", "O apagão" "', "Luz e cores", "Mudanças climáticas/aquecimento global" e "Desemprego".

A temática "Sol, luz e vida", tendo como eixo articulador conservação e degradação da energia, normalmente designadas como leis da termodinâmica, foi estruturada segundo a dinâmica dos denominados três momentos pedagógicos ${ }^{4}$ , descritos em Delizoicov et al. (2002). No trabalho realizado, o desenvolvimento com professores(as) em formação inicial (PFI) teve início com a combustão de uma pequena quantidade de gasolina. Nesse, a energia liberada, por exemplo, na forma de luz, consiste de energia emitida, há muito tempo, pelo Sol. Com essa compreensão trabalhamos, inicialmente sem maiores aprofundamentos, as transformações que a energia sofre desde a emissão pelo Sol até sua liberação na 
atividade realizada. Discutimos a propagação dessa energia por meio de ondas eletromagnéticas (trabalhamos transferência de energia por condução, convecção e irradiação), a fixação em moléculas orgânicas, no processo denominado fotossíntese, a formação de combustíveis fósseis e a destilação fracionada, chegando à gasolina.

No contato inicial com os professores em formação, denominado de "estudo em extensão", que durou em torno de quatro horas-aula, não houve a preocupação com o aprofundamento conceitual. Buscamos construir uma compreensão em extensão, fenomenológica, das transformações de energia envolvidas, destacando-se que, na formação dos combustíveis fósseis, por um longo período geológico, houve a fixação de carbono no subsolo, processo este revertido em pouco mais de cem anos pela sociedade industrial. Aspecto esse possivelmente vinculado a mudanças climáticas.

A complexidade do tema SLV requer o aporte de vários campos disciplinares, não restritos ao das assim chamadas ciências naturais. Assim, o aprofundamento conceitual, nos vários campos, está na dependência de profissionais/ professores desses campos engajados no trabalho. No presente trabalho, realizado basicamente com professores e estudantes de física, privilegiamos os conceitos físicos, havendo, em alguns momentos, a transgressão das cercas disciplinares, mediante o estudo de textos/conceitos de outros campos. Em outras implementações dessa temática, que não são objeto de análise aqui, com a presença de profissionais de vários campos disciplinares, trabalhamos outros conceitos e conhecimentos.

Em linhas gerais, considerando-se a complexidade da temática SLV, trabalhamos conhecimentos relacionados com: origem do universo (Big-Bang), fusão nuclear (Sol), espectro/radiação eletromagnética, fotossíntese, ciclo do carbono, formação de combustíveis fósseis, combustão/emissão de poluentes, leis da termodinâmica, massa específica, notação científica, medidas de volume, calor de combustão, trabalho, potência, rendimento em máquinas térmicas e reação de combustão da gasolina (combustão completa e incompleta). Além disso, trabalhamos reservas de petróleo estimadas nos diferentes países, consumo de energia em diferentes países e classes sociais, modelos alternativos ao petróleo no transporte de pessoas e cargas, causas e consequências do denominado efeito estufa e de sua intensificação.

O fenômeno das mudanças climáticas, possivelmente associado à emissão de carbono na atmosfera, não ocorre em qualquer organização social. Ou seja, uma compreensão mais ampla requer situá-lo no contexto da lógica consumista capitalista, sendo necessários, por exemplo, conhecimentos de história e sociologia.

\section{CURRÍCULOS TEMÁTICOS BALIZADOS POR FREIRE-CTS}

A aproximação Freire-CTS, conforme literatura anteriormente citada, foi sintetizada por Auler (2007) em três dimensões: (i) currículo estruturado em torno 
de temas/problemas reais; (ii) dimensão interdisciplinar no enfrentamento desses temas/problemas; (iii) busca da democratização de processos decisórios. Cabe destacar a polissemia presente no campo CTS. Assim, nesses três eixos, comparecem pressupostos desse campo que se aproximam de postulações freireanas.

Tendo como pressuposto a transformação da realidade, Freire (2005) defende que processos educativos problematizem essa realidade, identificando nela temas, os denominados "temas geradores", estruturantes de currículos temáticos. Para esse educador o processo educacional, que tem início com a busca desses temas, deve propiciar uma leitura crítica do mundo, com vistas à sua transformação. $\mathrm{Na}$ análise de Strieder (2012), Freire, ao fundamentar objetivos educacionais, enriquece o campo CTS, considerando que esses objetivos, segundo a autora, estão bastante difusos ou não explicitados nesse campo.

Se Freire contribui com objetivos educacionais, sua postulação de uma leitura crítica da realidade pode ser potencializada com uma compreensão crítica das interações entre Ciência-Tecnologia-Sociedade, algo fundamental na dinâmica social contemporânea e não aprofundado por Freire. Nesse sentido, a literatura que trabalha com a aproximação destes referenciais, considera relevante, por exemplo, a problematização da suposta neutralidade da Ciência-Tecnologia, aspecto presente no discurso do campo CTS, neutralidade entendida como legitimadora de modelos decisórios tecnocráticos. Também relativamente à referida aproximação, Santos (2008) considera que abordagens CTS, vinculadas ao referencial freireano, podem contribuir para resgatar a agenda política do movimento CTS.

Além disso, a articulação Freire-CTS coloca como desafio, no campo da educação científica, a necessidade de superação da concepção linear, a qual postula que primeiro o estudante (sociedade) precisa adquirir uma cultura científica para depois participar de processos decisórios. Entendemos, apoiados em Freire-CTS, que a constituição de uma cultura científica não é independente da participação social, mas que essas são dimensões articuladas, sendo processos que se realimentam mutuamente.

Parte substancial da produção em educação em ciências, envolvendo a articulação Freire-CTS, é oriunda de trabalhos desenvolvidos pelo Grupo de Estudos Temáticos em Ciência-Tecnologia-Sociedade (GETCTS) vinculado à Universidade Federal de Santa Maria. Em termos de repercussões educacionais, conforme já sinalizamos, temos argumentado que a articulação Freire-CTS tem como ponto central uma nova forma de compreender o currículo, numa perspectiva que avança para compreensões ampliadas sobre a organização escolar. Por exemplo, em pesquisa desenvolvida por Roso (2014) sobre construção de currículos em literatura brasileira do campo CTS, o autor identificou a presença significativa do referencial freireano. Contudo, como fragilidade, desafio a ser enfrentado, destaca a desconsideração, na construção curricular, de pressuposto central em Freire, ou seja, a investigação temática.

Auler et al. (2009) aprofundam aspectos pertinentes à natureza dos temas presentes em encaminhamentos freireanos e no campo CTS. A pesquisa foi guia- 
da pelas perguntas: o que é um tema de relevância social? Quem define o que é relevância social? Freire, ao postular a utilização de temas geradores, está falando a mesma coisa que os defensores do campo CTS? Os autores alertam para um necessário cuidado na extrapolação dos resultados, considerando, por exemplo, o conjunto limitado de trabalhos, do campo CTS, contemplados na pesquisa. Como síntese dessa pesquisa, os autores analisam cinco aspectos: a) abrangência dos temas; b) surgimento dos temas; c) disciplinas envolvidas na estruturação do tema; d) relação tema/conteúdo e e) conteúdo tradicional designado de tema.

Hunsche e Delizoicov (2011), considerando o crescimento desse encaminhamento, ou seja, a aproximação Freire-CTS, utilizando categorias do médico e epistemólogo Ludwick Fleck (2010), situam essa aproximação como uma possível instalação e disseminação de um novo "estilo de pensamento" através da circulação de ideias, conhecimentos e práticas.

Contudo, particularmente no âmbito do GETCTS, os autores têm destacado a importância de não negligenciar que a práxis freireana e os encaminhamentos CTS surgem em contextos bastante distintos. Em análise de Auler (2007), os pressupostos freireanos, apontando para a participação em processos decisórios, estão enraizados em países da América Latina e do continente africano. O movimento CTS repercutiu, de forma mais sistemática, no campo educacional, em contextos em que as condições materiais da população estavam razoavelmente satisfeitas. Contrariamente, na quase totalidade dos países da América Latina e da África, conjunto significativo da população é afetado por carência material. Além disso, ou melhor, vinculado a isso, a maioria desses países têm um histórico de passado colonial, cujas marcas se manifestam, por exemplo, naquilo que Freire (2005) denominou de cultura do silêncio, caracterizada pela ausência de participação do conjunto da sociedade em processos decisórios. A busca de enraizamento de processos educativos, em referenciais latino-americanos, além de Freire, tem evidenciado potencialidades do Pensamento Latino Americano em Ciência-Tecnologia-Sociedade (PLACTS), aspecto sinalizado, por exemplo, por Auler (2011).

Assim, a referida aproximação Freire-CTS, atenta a divergências e distanciamentos, busca complementariedades entre esses dois referenciais, sinalizando novos horizontes para processos educativos. Se, de um lado, não concordamos em pautar esses processos pelo que acontece no exterior, de outro, não podemos ignorar contextos mais amplos. Uma síntese dessa aproximação consiste nas três dimensões anteriormente citadas, ou seja, currículos estruturados em torno de temas/problemas reais; a dimensão interdisciplinar no enfrentamento destes temas/ problemas e a busca da democratização de processos decisórios.

\section{METODOLOGIA DA PESQUISA E RESULTADOS OBTIDOS}

A pesquisa foi de cunho qualitativo. $\mathrm{O}$ corpus de análise foi constituído das respostas dadas a um questionário (APÊNDICE A) respondido por duas turmas de PFI (Professores(as) em Formação Inicial), sendo que cada uma das turmas 
tinha 13 integrantes, totalizando 26 respondentes. Utilizamos a Análise Textual Discursiva (ATD) para sua análise. Para Moraes (2003), na ATD, a partir de um conjunto de textos produz-se um novo texto. Para esse autor, a ATD "pode ser compreendida como um processo auto-organizado de construção de compreensão em que novos entendimentos emergem de uma sequência recursiva de três componentes: desmontagem dos textos, estabelecimento de relações e captação do novo emergente" (MORAES, 2003, p. 191).

$\mathrm{Na}$ primeira etapa desse processo, a desmontagem dos textos, são extraídas dos originais (respostas dadas pelos PFI) unidades em que o analista irá atribuir "sentidos e significados" (MORAES, 2003, p. 192), denominadas de unidades textuais ou unidades de sentido. A segunda etapa do processo consiste em "reunir elementos semelhantes [...] nomear e definir as categorias" (MORAES, 2003, p. 197) de forma que, coerentemente com o pressuposto da primeira etapa, essa categorização é realizada considerando os referencias teóricos do analista (no caso da presente pesquisa, Freire e CTS, sendo a aproximação desses dois referenciais sintetizada nas três dimensões citadas anteriormente) e os objetivos da pesquisa (apresentados anteriormente). Já na terceira etapa do processo, captando o novo emergente, as compreensões e teorizações atingidas em relação aos fenômenos estudados serão expressas e validadas.

Dos elementos semelhantes, reunidos na análise das unidades textuais, o que caracteriza a segunda etapa da ATD (MORAES, 2003), resultaram três categorias, denominadas: "Da fragmentação disciplinar à interdisciplinaridade"; "Temas da realidade dos estudantes como ponto de partida"; e "Abordagem temática: reconfiguração curricular ou nova metodologia?".

\section{DA FRAGMENTAÇÃO DISCIPLINAR À INTERDISCIPLINARIDADE}

O processo de análise das compreensões desses professores em formação inicial (PFI) revelou quão enraizada está a lógica disciplinar. Revelou angústias, medos, rejeições e entusiasmos por parte dos professores. Da análise, evidenciamos, mesmo após o processo vivenciado, compreensões confusas sobre interdisciplinaridade. Possivelmente isso decorre, também, da polissemia do termo presente na literatura. Expressões como "então devo saber tudo de todas as disciplinas?" revelam determinada concepção, ou seja, a do professor polivalente. Outra compreensão, também presente na literatura, pode ser sintetizada como "relação entre as disciplinas". Já uma terceira concepção sobre interdisciplinaridade, assumida no encaminhamento curricular da temática SLV, está ancorada em pressupostos freireanos.

Nessa última concepção, ao invés do professor polivalente, a interdisciplinaridade pressupõe a colaboração integrada de diferentes campos disciplinares que trazem sua contribuição para a análise de determinado tema (DELIZOICOV; ZANETIC, 2002). Ou, de acordo com Pernambuco (1994), ela "surge, sim, do confronto entre diferentes áreas, referenciais, na tentativa de resolver um pro- 
blema concreto que é assumido como tal por todos os participantes da relação" (PERNAMBUCO, 1994, p. 116).

$\mathrm{Na}$ análise realizada, há falas que revelam entusiasmo com abordagens interdisciplinares, destacando o "quão fundamental é que o aluno possa relacionar os assuntos que aprende com o seu cotidiano e também com as outras disciplinas que estuda" (PFI-T1-A) ${ }^{5}$ e, também, "torna a ciência mais interessante de ser estudada, pois traz a realidade e interdisciplinaridade para o entendimento do tema" (PFI-T1-B). Outro PFI pôde rever suas concepções quanto às relações entre áreas do conhecimento. Em suas palavras, "achava que cada área não dependeria de outras e hoje vejo que cada área é vinculada à outra” (PFI-T1-C).

Compreendendo interdisciplinaridade como relacionamento entre disciplinas, segundo um dos PFI, "nesta temática a física está relacionada com as outras disciplinas, ficaria muito difícil aplicá-la sem que os professores das outras disciplinas não estivessem no mesmo conteúdo" (PFI-T2-A). Reforçamos que, em nosso entendimento, a interdisciplinaridade vai muito além de relacionar disciplinas, do "casar conteúdos/disciplinas" como, por exemplo, trabalhar concomitantemente movimento retilíneo uniforme, na disciplina de física, com equações de primeiro grau em matemática.

Há um conjunto de falas, expressando entusiasmo, nas quais a compreensão de "casar disciplinas" é marcante. Em termos de exemplificação, temos falas como "os conceitos englobados se encaixam, um complementa o outro" (PFI-T1-D) ou o reconhecimento da possibilidade de "visualizar a integração das demais disciplinas com a física" (PFI-T2-F).

Conforme já dito anteriormente, a defesa da interdisciplinaridade, no referencial freireano, está associada a currículos temáticos, os quais sinalizam quais conhecimentos disciplinares são pertinentes e necessários em sua configuração, processo que pode ser ilustrado pelo Movimento de Reorientação Curricular, desenvolvido pela Secretaria Municipal de Educação da cidade de São Paulo (PONTUSCHKA, 2002; SAMPAIO et al., 1994).

Coerente com essa compreensão, situam-se alguns dos PFI. Ou seja, a formação de coletivos interdisciplinares, nos quais distintos campos disciplinares iluminam distintas faces do tema/problema, estando implícita, na análise, a compreensão quanto às limitações da atual organização do espaço-tempo da escola. Os respondentes assim colocam: "eu daria essa temática em aulas extras junto com os professores de Biologia e Química” (PFI-T2-D); “a temática poderia ser apresentada por uma equipe de professores (física, matemática, história, química, etc.), [...] elaborada, desenvolvida, aprimorada, difundida" (PFI-T2-E). Essas falas são animadoras considerando que podem constituir aprendizagens a serem potencializadas, impulsionadoras de mudanças mais radicais na organização espaço-temporal da escola e na futura atuação desses PFI.

Referindo-se a essa compreensão de interdisciplinaridade, Delizoicov e Zanetic (2002) destacam que ela "pressupõe um procedimento que parte da ideia de que as várias ciências deveriam contribuir para o estudo de determinados temas 
que orientam todo o trabalho escolar" (DELIZOICOV; ZANETIC, 2002, p. 13). Esses autores não defendem a ideia do professor polivalente, aquele que deve "saber tudo de todas as disciplinas", o que não exclui que, no processo, como ocorreu no desenvolvimento da temática SLV, seja necessário transgredir as fronteiras disciplinares e aventurar-se em estudos sobre outros campos, como, por exemplo, fotossíntese, reações de combustão, lógica consumista vigente na sociedade industrial capitalista (incompatível com uma efetiva sustentabilidade), dentre vários outros.

Sem se situarem, especificamente, numa das três compreensões sobre interdisciplinaridade anteriormente elencadas, há um grupo de estudantes que manifestam ganhos cognitivos decorrentes da interdisciplinaridade presente na temática SLV. Por exemplo, um PFI conseguiu "aprofundar conhecimentos em outras áreas como química e biologia, na qual tinha grandes dificuldades. [...] [pôde] encaixar conhecimentos de conceitos que estavam um pouco soltos como conservação da energia e trabalho" (PFI-T1-F). Ainda, o desenvolvimento "possibilita a interdisciplinaridade, facilitando a compreensão do aluno, e contribuindo positivamente na educação, [...] contribuem mais para o aprendizado do aluno" (PFI-T1-G).

A rejeição, o receio da mudança e o medo da perda da identidade do professor de física também comparecem em vários posicionamentos, os quais consideram que "a questão interdisciplinar muitas vezes foi em excesso" (PFI-T2-B), "mesmo concordando com a ideia de interdisciplinaridade, a temática fugiu dos conceitos físicos” (PFI-T2-C).

\section{TEMAS DA REALIDADE DOS ESTUDANTES COMO PONTO DE PARTIDA}

"Contextualizar" e "usar o cotidiano dos estudantes" são termos que foram incorporados ao discurso pedagógico. Contudo, muitas vezes, são usados de forma genérica, em distintas concepções educacionais, sem aprofundamento teórico. Muitas vezes, representam artifícios pedagógicos usados, por exemplo, para ilustrar, ao final do processo, conceitos presentes em currículos cristalizados. No trabalho desenvolvido a perspectiva é outra:

\footnotetext{
Meu pensamento antes de fazer esta disciplina era, penso eu, como o da maioria, ensinar os conceitos para aplicar depois. Hoje vejo e levarei comigo em minha formação profissional que para ensinarmos precisamos partir de um assunto do mundo deles, em que eles vivem... (PFI-T1-C).
}

Essa fala contém elementos que se aproximam da concepção educacional subjacente à abordagem temática postulada neste trabalho. Depreende-se dela que, inicialmente, o PFI entendia o contexto do estudante como aplicação dos conceitos científicos, sendo que, com o trabalho desenvolvido, constatou a importância dessa reorientação. O contexto passa a constituir, assim, o ponto de partida.

Por outro lado, mesmo após o trabalho desenvolvido, persistem compre- 
ensões dúbias, genéricas. Isso foi identificado em falas de PFI nas quais os respondentes afirmam que "[...] foi possível interligar conceitos físicos, Sol, luz e vida usando exemplos cotidianos, o que fortemente facilita a compreensão” (PFI-T2-G), e também, “[...] ficou mais claro o quão fundamental é que o aluno possa relacionar os assuntos que aprende com o seu cotidiano [...]” (PFI-T1-A).

Defendemos que o contexto, a realidade vivida pelo estudante, represente o ponto de partida do processo educacional e também o ponto de chegada, já com um olhar ampliado, crítico sobre ela. Há falas que sinalizam uma concepção curricular que se aproxima daquela por nós assumida. Por exemplo: “[...] acredito ser indispensável ao menos a tentativa de utilizar temas reais e atuais do aluno na abordagem em sala de aula para o ensino de física" (PFI-T1-G). Ou ainda, destacando que a temática trabalhada torna a ciência "[...] mais interessante de ser estudada, pois traz a realidade e interdisciplinaridade para o entendimento do tema e usando esse para desenvolver conteúdos importantes da ciência” (PFI-T1-B).

O trabalho desenvolvido com os futuros professores deixou indicativos de que alguns assumiram a possibilidade de trabalhar com temas da realidade do estudante, e, principalmente, concebendo-os como ponto de partida na construção do conhecimento. No entanto, cabe problematizar o uso genérico que fazem do termo cotidiano: “[...] uma física voltada para o cotidiano [...]” (PFI-T1-D). De acordo com Moraes (2008), um currículo efetivamente contextualizado, superando reducionismos em relação ao apelo ao cotidiano, deveria partir do que os estudantes conseguem falar e expressar sobre o mundo, sobre a realidade vivida.

Conforme já sinalizado anteriormente, com o trabalho desenvolvido junto aos PFI houve manifestações de entusiasmo, de engajamento, aparecendo sinais da categoria freireana denominada de curiosidade epistemológica, isto é, uma predisposição positiva para o prender, traduzida pelo querer conhecer. $\mathrm{Na}$ fala de um PFI, conceber a realidade vivida como ponto de partida motiva o estudante: "uma boa maneira de fazer o aluno se interessar mais na aula. Pois envolve assuntos mais próximos da realidade dos alunos" (PFI-T2-H). Freire e Shor (1986) criticam o currículo padrão, tradicionalmente utilizado, que lida com a motivação como se ela fosse externa ao ato de aprender, ou seja, as provas, as disciplinas, os castigos, as recompensas, as promessas de emprego no futuro. Para os autores, a motivação deve estar no problema, no tema a ser conhecido, no conteúdo a ser apreendido, no próprio ato de estudar. Em síntese, nas compreensões dos PFI trazidas nesse parágrafo, há sinalizações de que esses constataram dimensões relevantes (no desenvolvimento do tema SLV) para, em sua atuação profissional, aguçar a denominada curiosidade epistemológica.

\section{ABORDAGEM TEMÁTICA: RECONFIGURAÇÃO CURRICULAR OU NOVA METODOLOGIA?}

Já em trabalhos anteriores, por exemplo, Muenchen (2006) identificou uma tendência em rotular como uma nova metodologia tudo de diferente que ocorre na escola, inclusive mudanças curriculares. No presente trabalho, mesmo 
após o desenvolvimento da proposta, em alguns casos, persistiu essa compreensão. Já outros PFI evidenciaram superação do que denominamos de reducionismo metodológico.

Nossa análise contém evidências de que houve problemas no entendimento, por parte de alguns PFI, do que foi proposto, mesmo sendo trabalhado e discutido que o processo desenvolvido envolvia reconfigurações curriculares, algo não restrito a métodos e técnicas de ensino. Alguns PFI, ao final, continuavam concebendo a abordagem temática como uma nova metodologia, ou seja, "foi um método de ensino bem interessante que nós aprendemos” (PFI-T1-A). Ou então, "foi bem produtivo, pois a metodologia foi apresentada na prática e depois analisada mais a fundo, com auxílio de textos e prática dissertativa” (PFI-T1-B). Independentemente da nomenclatura, da terminologia utilizada, comparecem indicativos de que o processo foi avaliado como tendo potencial para práticas futuras. Outro PFI revela que "com certeza na realização de estágio procurarei introduzir este tipo de metodologia. Ela é muito eficiente e com certeza capaz de fazer o aluno a interessar-se pela Física. [...]" (PFI-T1-H).

É alentador o fato de que a maioria passou a conceber a abordagem temática como uma possibilidade de configuração curricular. Esta foi entendida, por alguns, como um possível caminho para a solução de problemas do campo educacional visto que pode contribuir "[...] para uma formação educacional mais ampla, capaz de encarar desafios, fazer questionamentos físicos, debater assuntos reais, do dia-a-dia dos alunos [...] eu considero possível levar esse currículo adiante" (PFI-T1-E). Essa configuração foi entendida, também, como algo interessante e desafiador: "acho fundamental o currículo ser voltado a temas, pois torna a dinâmica do ensino mais interessante e proporciona também ao professor a 'evolução conceitual' tornando as aulas interessantes e desafios diários” (PFI-T1-B).

Houve manifestação, aqui considerada central, que, de um lado, revela compreensão de que os problemas educacionais vão muito além de novos métodos e técnicas de ensino, remetendo ao campo do currículo e, de outro, coragem e convicção da possibilidade de outras configurações curriculares. Ou, nas palavras do licenciando, "[...] os atuais currículos usados nas escolas estão prontos, mas não é imutável” (PFI-T1-F).

\section{CONSIDERACְ̃̃ES FINAIS}

Uma avaliação mais abrangente dessa concepção educacional, do currículo temático, tem sido prejudicada, dentre outros aspectos, pela organização espaço-temporal da escola, o que tem comprometido a realização de práticas educativas em maior escala. O que tem sido exequível são intervenções pontuais, sendo, contudo, o horizonte a busca de currículos efetivamente temáticos.

Com a pesquisa que realizamos, buscamos identificar desafios e possibilidades e, acima de tudo, indicadores da plausibilidade desse horizonte. Os resultados, expressando posicionamentos de professores(as) em formação inicial sobre 
currículos temáticos, sinalizam, por exemplo, o desafio que consiste na necessidade da problematização da compreensão de prática profundamente enraizada, sintetizada no que denominamos de reducionismo metodológico. Mesmo após o trabalho desenvolvido, a retórica de abordagem temática como uma nova metodologia, não foi superada por parte dos licenciandos.

Essa retórica e/ou compreensão é coerente com uma construção histórica que reduz o papel do professor(a) a cumprir, a executar currículos. Assim, professores(as) posicionam-se diante de currículos como algo a ser cumprido, vencido. Tornam-se, dessa forma, reféns deles. Sua formação e atuação ficam restritas ao aspecto metodológico. Ou seja, buscam-se novas metodologias, novas respostas para as questões: como ensinar melhor, como executar melhor um currículo pronto. Contudo, sintetizando sinalização promissora identificada no trabalho realizado, um dos futuros professores destacou, conforme já referido, “[...] os atuais currículos usados nas escolas estão prontos, mas não é imutável".

Se a superação desse reducionismo metodológico é essencial, a dinâmica de currículos temáticos, quando alicerçada em pressupostos que buscam a constituição de uma cultura de participação em processos sociais mais amplos, amplia o espectro de desafios. Temas, problemas sociais contemporâneos, nos quais, em geral, a dimensão científico-tecnológica tem presença marcante, não são compreensíveis, enfrentáveis por campos disciplinares isolados. Ainda, o desafio é maior. Independentemente da concepção e/ou encaminhamento dado à prática interdisciplinar, se esta for executada apenas com conhecimentos e disciplinas que compõem a maioria dos atuais currículos da Educação Básica, a possibilidade de constituição da postulada cultura de participação poderá estar seriamente comprometida.

Iluminar temas, problemas contemporâneos, apenas com conhecimentos já presentes nos currículos tradicionais possivelmente terá como resultado a prevalência de zonas de escuridão. A maioria dos problemas contemporâneos, como mudanças climáticas, são complexos, abertos, dinâmicos, sendo a incerteza elemento constituinte. Nesse sentido, Watanabe-Caramello e Strieder (2011) concluem que currículos pautados unicamente, pela linguagem da certeza, da previsibilidade, da determinação, fragilizam a compreensão e enfrentamento de temáticas socioambientais.

Além disso, entendemos que permanecerá fragilizada qualquer concepção e/ou prática interdisciplinar que se reduza ao campo das assim chamadas ciências da natureza. Conforme ressaltamos na análise dos resultados da pesquisa, temas contemporâneos, como mudanças climáticas, assim como outras dimensões da degradação socioambiental, não ocorrem em todo e qualquer modelo de sociedade, mas, sim, na sociedade capitalista contemporânea. Portanto, reduzir sua compreensão e busca de enfrentamento unicamente no campo das chamadas ciências naturais representa, no nosso entender, o endosso a concepções cientificistas, tecnocráticas. Reduzir a análise, praticar interdisciplinaridade sem os campos da história, sociologia, economia e filosofia, dentre outros, deixará zonas escuras e, 
possivelmente, o pano de fundo motivador dos problemas obscurecidos.

Currículos temáticos, estruturados mediante problemas reais, exigem, para sua compreensão e enfrentamento, vários campos disciplinares. Conhecimentos disciplinares atuam como luzes que iluminam as múltiplas dimensões que constituem a complexidade dos mesmos. Contudo, qual a margem de manobra para a implementação de currículos com essa característica, demandando ações coletivas, trabalhos interdisciplinares, se o espaço-tempo da escola é pautado pela fragmentação, por currículos disciplinares? Esses, assim como vários outros condicionantes, não podem ser negligenciados, exigindo ações que vão além de intervenções pontuais, sendo o horizonte uma profunda reorganização do espaço-tempo da escola. Ações mais pontuais, como a que está sendo analisada neste artigo, envolvendo a formação de educadores, são sinalizadoras de caminhos, de desafios e potencialidades que podem desembocar em transformações mais profundas.

Uma terceira dimensão marcante na pesquisa realizada, relacionada às discussões anteriores, é o uso do cotidiano na educação, considerado, em alguns âmbitos, como um novo salvacionismo - cotidiano, numa perspectiva reducionista, assumido como motivação e/ou ilustração de conteúdos presentes nos currículos tradicionais, os quais permanecem intocáveis. Cotidiano é por nós entendido como local de manifestação de contradições sociais mais amplas, como local de identificação de temas/problemas estruturantes de currículos. Temas esses que carregam a complexidade presente nesse cotidiano. Cotidiano no qual, na nossa compreensão, manifestam-se temas/problemas que têm dimensões inéditas, como as já citadas mudanças climáticas, inseridas num contexto de degradação socioambiental mais amplo. Nesse cenário, não é necessário, também, problematizar limitações de um discurso, de uma prática cristalizada na educação, qual seja, a escola como local de apropriação do conhecimento, da cultura produzida historicamente? Esse conhecimento, transformado em universal, foi produzido para atender demandas muitas vezes de contextos e interesses específicos do passado. Não é razoável imaginar que problemas como os anteriormente mencionados, novos, inéditos, exigiriam, para sua compreensão e enfrentamento, também conhecimentos novos, inéditos?

Ainda em relação ao aspecto anterior, se o papel da escola ficar reduzido à apropriação da cultura, parece que a escola continuará a exercer o papel de perpetuadora do status quo. Não seria prudente atribuir à escola o papel de problematizar a cultura - cada vez mais marcada pela lógica consumista, geradora de insustentabilidade socioambiental? Possivelmente, numa perspectiva de transformação da realidade, tal qual postulada por Freire, a escola, articulada como outros atores sociais, seja um espaço possível de produção de uma nova cultura, uma cultura pautada por valores de participação, de constituição de sociedades efetivamente sustentáveis.

As sinalizações, os questionamentos, retomados no final deste artigo constituem dimensões que estão ficando mais evidentes, também, porque estamos avançando na práxis com currículos temáticos. Entendemos tais dimensões não 
devem ser concebidas como impossibilidades, mas como desafios a serem enfrentados. Sem desconsiderar condicionamentos que a escola sofre da organização do espaço social mais amplo ${ }^{6}$, buscamos, no contexto da construção de uma cultura de participação, o que Freire denominou de inédito viável, ou seja, a busca de soluções ainda não percebidas, o que consiste numa nova organização do espaço-tempo da escola com ressonâncias com o espaço social mais amplo.

A constituição de uma cultura de participação, potencializada por processos educativos, não pode ser desvinculada de problemas crônicos da educação brasileira, como os citados no início: evasão, repetência e falta de significado atribuído à escola. Mesmo com intervenções, ainda pontuais, a concepção e a execução de currículos temáticos têm revelado sinalizações promissoras, sendo um maior engajamento por parte dos estudantes nas atividades realizadas uma dimensão recorrente. Esse maior engajamento, possivelmente decorrente da maior ressonância entre escola (currículo) e o "mundo da vida" dos estudantes, pode estar indicando um caminho para reduzir a evasão e aumentar a atribuição de significativo às ações executadas, processo que pode culminar com ganhos cognitivos, o que reduzirá a repetência - ganhos cognitivos potencializados e potencializadores de uma cultura de participação.

\section{NOTAS}

1 Apoio CAPES e CNPq.

${ }^{2} \mathrm{O}$ artigo consiste em aprofundamentos de trabalho apresentado no II Seminário Internacional de Educação em Ciências, realizado em Rio Grande/RS, em 2012 (ROSA, ROSO e SANTOS, 2012).

${ }^{3}$ Tema decorrente da crise de energia elétrica, ocorrida no Brasil em 2001 e de um "apagão" que afetou a cidade de Santa Maria - RS em determinada noite.

${ }^{4}$ Os três momentos pedagógicos são constituídos de três etapas: 1) Problematização Inicial: momento em que são apresentadas e problematizadas situações e/ou questões, presentes na vivência dos estudantes, relacionadas ao tema em estudo; 2) Organização do Conhecimento: são trabalhados conhecimentos pertinentes à compreensão do tema/ problema sob orientação do professor e 3) Aplicação do Conhecimento: momento em que são rediscutidas tanto as situações iniciais, quanto outras não diretamente ligadas à problematização inicial.

${ }^{5}$ Sempre que nos referirmos às falas, às expressões textuais dos professores, utilizaremos a sigla PFI ao lado da identificação de cada turma, T1 ou T2, e vincularemos cada PFI a uma letra do alfabeto. Assim, por exemplo, teremos as seguintes referências: PFI-T1-A, PFI-T2-C, PFI-T2-F, FPI-T1-B, etc.

${ }^{6}$ Por exemplo, o Movimento Todos pela Educação defende um currículo nacional pautado por valores alinhados à lógica empresarial (www.todospelaeducacao.org.br). 


\section{REFERÊNCIAS}

AULER, D. Interações entre Ciência-Tecnologia-Sociedade no contexto da formação de professores de ciências. 2002. 258 f. Tese (Doutorado em Educação) - Centro de Educaçao, Universidade Federal de Santa Catarina, Florianópolis, 2002.

AULER, D. Enfoque Ciência-Tecnologia-Sociedade: pressupostos para o contexto brasileiro. Ciência \& Ensino, Campinas, v.1, n. especial, p. 01-20, 2007.

AULER, D. Novos caminhos para a educação CTS: ampliando a participação. In SANTOS, W. L. P. dos; AULER, D. (Org.). CTS e educação cientifica: desafios, tendências e resultados de pesquisas. Brasília: Universidade de Brasília, p. 73-98, 2011.

AULER, D. et al.Transporte particular x coletivo: intervenção curricular pautada por interações entre Ciência-Tecnologia-Sociedade. Enseñanza de las ciencias, Granada, ESP, n. extra, p. 1-5, 2005.

AULER, D. et al. Abordagem Temática: natureza dos temas em Freire e no enfoque CTS. Alexandria: Revista de Educação em Ciência e Tecnologia, Florianópolis, v. 2, n. 1, p. 67-84, 2009.

CHARLOT, B. A construção social da noção de fracasso escolar: do objeto sociomidiático ao objeto de pesquisa. In: ARROYO, M.; ABRAMOWICZ, A. A reconfiguração da escola: entre a negação e a afirmação de direitos. Campinas: Papirus, 2009.

DALMOLIN, A. M. T. et al. Movimento CTS e Paulo Freire em um repensar da educação em ciências. In: SEMINÁRIO INTERNACIONAL DE EDUCAÇÃO EM CIÊNCIAS (SINTEC), 1. 2011, Rio Grande - RS. Anais... Rio Grande, RS: FURG/NUEPEC, 2011.

DELIZOICOV, D. et al. Ensino de ciências: fundamentos e métodos. São Paulo: Cortez, 2002.

DELIZOICOV, D.; ZANETIC, J. A proposta de interdisciplinaridade e o seu impacto no ensino municipal de $1^{\circ}$ Grau. In: PONTUSCHKA, N. Ousadia no diálogo: interdisciplinaridade na escola pública. $4^{\mathrm{a}}$ Ed. São Paulo: Edições Loyola, 2002.

FLECK, L. Gênese e desenvolvimento de um fato cientifico. Belo Horizonte: Fabrefactum, 2010.

FREIRE, P. Pedagogia da esperança: um reencontro com a pedagogia do oprimi-

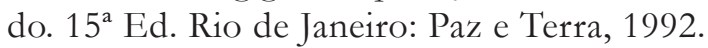

. Pedagogia do oprimido. 48 ${ }^{\mathrm{a}}$ Ed. Rio de Janeiro: Paz e Terra, 2005.

FREIRE, P.; SHOR, I. Medo e ousadia: o cotidiano do professor. Rio de Janeiro: Paz e Terra, 1986.

HUNSCHE, S.; DELIZOICOV, D. A abordagem temática na perspectiva da articulação Freire-CTS: um olhar para a instauração e disseminação da proposta. In: ENCONTRO NACIONAL DE PESQUISA EM EDUCAÇÃO EM CIÊNCIAS (ENPEC), 8., 2011, Campinas - SP. Anais... Rio de Janeiro: ABRAPEC, 2011. 
MONTEIRO, R. et al. A Abordagem CTSA sob a perspectiva dos temas geradores em Freire para formação continuada de professores de ciências: um campo de conflitos simbólicos na região de Angra dos Reis. Ensino, saúde e ambiente (REMPEC), Niterói, RJ, v. 3, n. 2,

p. 155-66, 2010.

. Cotidiano no ensino de química: superações necessárias. In: GALIAZZI, Maria do Carmo et al. (Orgs.). Aprender em rede na educação em ciências. Ijuí, RS: Ed. Unijuí, 2008.

MORAES, R. Uma tempestade de luz: a compreensão possibilitada pela análise textual discursiva. Ciência \& Educação, Bauru, SP, v. 9, n. 2, p. 191-211, 2003.

MUENCHEN, C. Configurações Curriculares mediante o enfoque CTS: Desafios a serem enfrentados na EJA. 2006. 129 f. Dissertação (Mestrado em Educação) - Universidade Federal de Santa Maria, Programa de Pós-Graduação em Educação, Santa Maria, RS, 2006.

NASCIMENTO, T. G.; VON LINSINGEN, I. Articulação entre o enfoque CTS e a pedagogia de Paulo Freire como base para o ensino de ciências. Convergência, Toluca, MEX, v. 13, n. 42, p. 95-116, 2006.

PERNAMBUCO, M. Educação e escola como movimento: do ensino de ciências à transformação da escola pública. 1994. 235 f. Tese (Doutorado em Educação) - Faculdade de Educação, Universidade de São Paulo, São Paulo, 1994.

PONTUSCHKA, N. Ousadia no diálogo: interdisciplinaridade na escola pública. $4^{\mathrm{a}}$ Ed. São Paulo: Edições Loyola, 2002.

ROSA, S. E. da et al. Abordagem temática na perspectiva da aproximação Freire-CTS: limites e possibilidades de engajamento de professores em formação inicial. In: II Seminário Internacional de Educação em Ciências (SINTEC), 2012, Rio Grande, RS. Anais... Rio Grande - RS: FURG/NUEPEC, 2012.

ROSO, C. C. et al. Práticas educativas balizadas por Freire e CTS. In: VIII Encontro Nacional de Pesquisa em Educação em Ciências (ENPEC), 2012, Campinas. Anais. Rio de Janeiro: ABRAPEC, 2011.

ROSO, C. C. A participação na construção do currículo: práticas educativas vinculadas ao movimento CTS. 2014. 99 f. Dissertação (Mestrado em Educação) - Centro de Educação, Universidade Federal de Santa Maria, Santa Maria, RS, 2014.

SAMPAIO, M. das M. F. et al. Interdisciplinaridade no município de São Paulo. Brasília: INEPE, 1994.

SANTOS, R. A. dos et al. Enfoque CTS e Paulo Freire: referenciais para repensar a educação em ciências. In: SEMINÁRIO IBERO-AMERICANO CIÊNCIA-TECNOLOGIA-SOCIEDADE NO ENSINO DAS CIÊNCIAS (SIACTS-EC), 2., 2010, Brasília. Anais... Brasília: UnB, 2010.

SANTOS, W. L. P. dos. Educação científica humanística em uma perspectiva Freireana: resgatando a função do ensino de CTS. Alexandria: revista de educação em ciência e tecnologia, Florianópolis, v. 1, n. 1, p. 109-31, 2008. 
STRIEDER, R. B. Abordagens CTS na educação cientifica no Brasil: sentidos e perspectivas. 2012. 283 f. Tese (Doutorado em Ensino de Ciências) - Faculdade de Educação, Instituto de Física, Instituto de Química, Instituto de Biociências, Universidade de São Paulo, São Paulo, 2012.

WATANABE-CARAMELLO, G.; STRIEDER, R. B. Elementos para desenvolver abordagens temáticas na perspectiva socioambiental complexa e reflexiva. Revista electrónica de enseñanza de las ciencias (REEC), Vigo, ESP, v. 10, n. 03, p. 587-608, 2011.

WATANABE-CARAMELLO, G.et al. Desafios e Possibilidades para a abordagem de temas ambientais em aulas de física. Revista brasileira de pesquisa em educação em ciências (RBPEC), São Paulo, SP, v. 12, n. 1, p. 205-22, 2012.

\section{Data de recebimento: 04/07/2014}

Data de aprovação: $16 / 05 / 2015$

\section{Contato:}

Caetano Castro Roso

Programa de Pós-Graduação em Educação Científica e Tecnológica

Centro de Ciências Físicas e Matemáticas - UFSC - Trindade, Florianópolis, SC - Brasil

CEP 88040-900

Email: caetanoroso@gmail.com 